\title{
Coronal approach for rehabilitative orbital decompression in Graves' ophthalmopathy
}

\author{
Rachel Kalmann, Maarten Ph Mourits, Jeroen P van der Pol, Leo Koornneef
}

\begin{abstract}
Aims-To determine the effectiveness and safety of three wall orbital decompression by the coronal approach in Graves' ophthalmopathy.

Methods-The records of 125 patients with Graves' ophthalmopathy, who had undergone three wall orbital decompression by coronal approach between April 1984 and October 1993, were studied retrospectively. Special attention was paid to proptosis reduction, changes in ocular motility, and complications.

Results-The preoperative Hertel values ranged from 15 to $30 \mathrm{~mm}$ (mean 22.43 $\mathrm{mm})$. The mean proptosis reduction was $4.34 \mathrm{~mm}$ (range 0-10 $\mathrm{mm}$ ). Proptosis reduction in patients with preoperative Hertel values higher than $27 \mathrm{~mm}$ was significantly more than in patients with preoperative values between 25 and $27 \mathrm{~mm}$ $(p<0.05)$. This last group showed significantly more proptosis reduction than patients with preoperative Hertel values of 23 and $24 \mathrm{~mm}(\mathrm{p}<0.01)$. Postoperatively, $3.2 \%$ of the patients showed new diplopia in primary and/or reading position. In $4 \%$ of the patients with normal ocular motility preoperatively, diplopia in the extreme directions of gaze developed. In $4 \%$ of the patients, preoperative motility disturbances decreased or disappeared postoperatively.

Conclusion-Three wall orbital decompression by coronal approach is a safe and effective technique, to achieve proptosis reduction in patients with Graves' ophthalmopathy, with fewer complications than other techniques thus far described. (Br F Ophthalmol 1997;81:41-45)
\end{abstract}

Ophthalmology (Orbital Centre), University of Amsterdam R Kalmann $\mathrm{J} P$ van der Pol L Koornneef

Department of Ophthalmology, University of Utrecht $\mathrm{M} \mathrm{Ph}$ Mourits

Correspondence to: R Kalmann, MD, Department of Ophthalmology, Orbital Centre, University of Amsterdam, Meibergdreef 9, $1105 \mathrm{AZ}$ Amsterdam Zuidoost, the Netherlands. wall decompressions have been advocated as well. ${ }^{2-5812131516}$ The most striking complication of transantral two wall decompression is the
The indications for orbital decompression in ' ophthalmopathy have changed over the and corneal exposure are still the most citerature, ${ }^{1-9}$ an increasing number of patients raves' ophthalmopathy undergo orbit decompression for cosmetic rehabilitative rea(see Figs 1 and 2)..$^{10-1}$ decompression is two wall decompression via the transantral approach as described by Walsh and Ogura in 1957. ${ }^{1}$ Two wall decompressions via other approaches and one, three, and four increased incidence of postoperative imbalance of the extraocular muscles, ranging from 25 to $64 \% .^{79141617}$

In our clinic 125 patients with Graves' ophthalmopathy underwent a three wall orbital decompression by the coronal approach, as described by Tessier, Krastinova and Rodallec, and later by Koornneef and Mourits, for cosmetic rehabilitative reasons. ${ }^{18-20}$ The effectiveness, by means of proptosis reduction, and safety of this technique are studied retrospectively and discussed.

\section{Patients and methods}

The clinical characteristics of all 125 patients, operated between the 1984 and 1993, are given in Table 1. All 125 patients underwent bilateral orbital decompression for rehabilitative reasons. Five surgeons performed the operation. Ninety four patients had been treated before surgery (21 with prednisone, 30 with retrobulbar radiotherapy, and 43 with both prednisone and radiotherapy). Thirty one patients did not receive any previous treatment. The mean duration of the ophthalmopathy before the operation was 4.35 years.

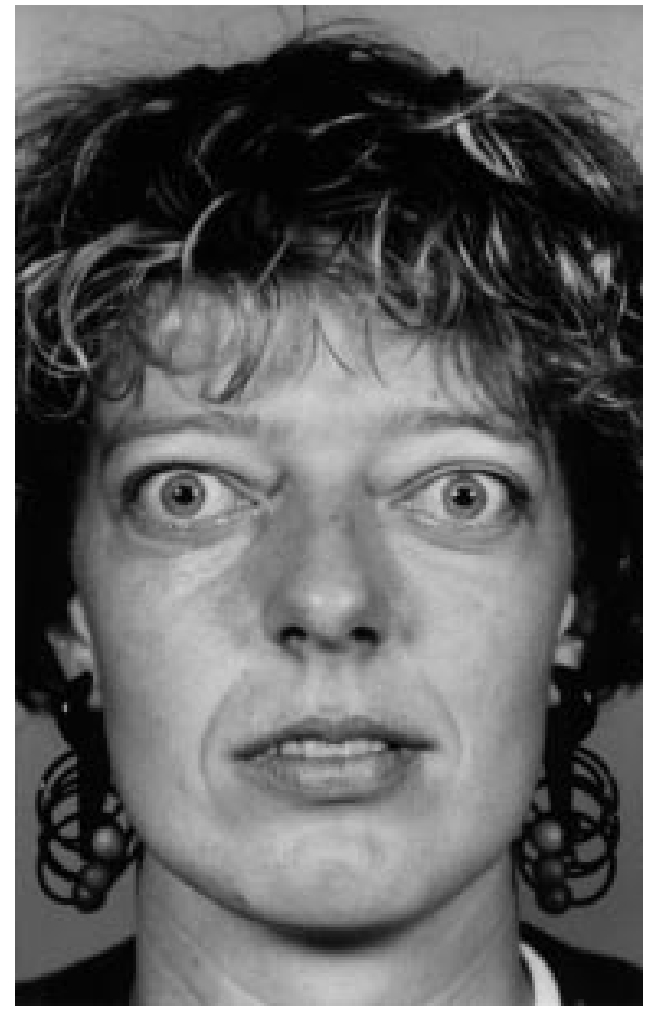

Figure 1 Preoperative appearance of a patient who underwent a three wall orbital decompression by coronal approach. (Reproduced with the permission of the patient.) 


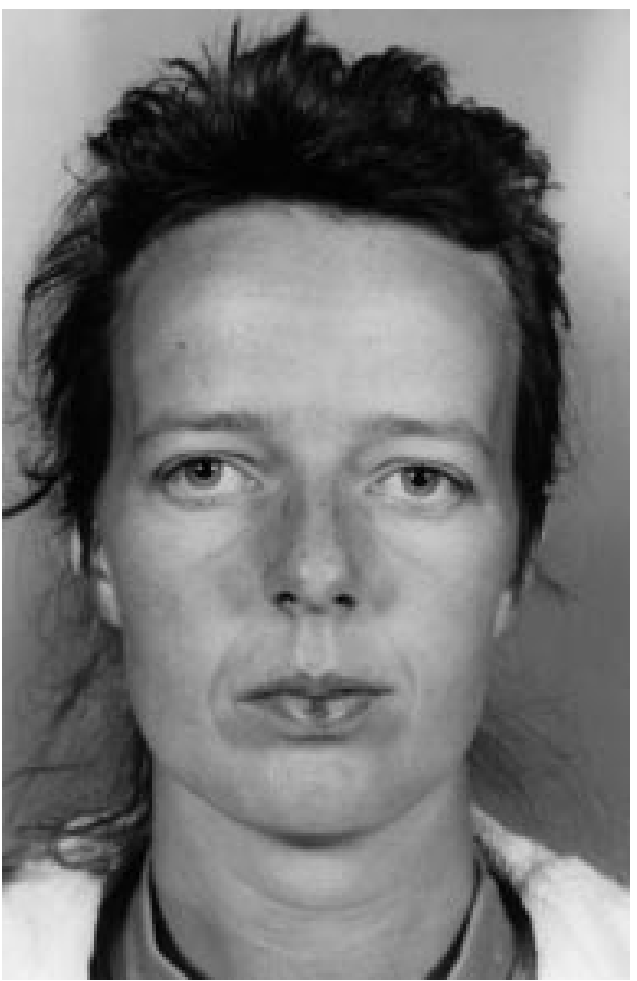

Figure 2 Postoperative appearance of patient in Figure 1. (Reproduced with the permission of the patient.)

Pre- and postoperative orthoptic examination consisted of determination of monocular ductions, Maddox cross motility, and field of binocular single vision. Statistical evaluation was performed using the two tailed $t$ test.

The surgical technique of the three wall orbital decompression by the coronal approach was that as described by Mourits, Koornneef, and van der Pol, ${ }^{11} 2021$ although minor changes have arisen. After shaving a strip of hair, a skin muscle incision is made through the scalp 10 $\mathrm{mm}$ behind the hair border from ear to ear. At the same level the periosteum is incised and the subgaleal flap is turned down to the supraorbital rim, avoiding injury to the supraorbital nerve. The periorbita is dissected off the orbital bones, including the trochlea. The temporalis muscle is partially freed from its origin, leaving enough tissue for suturing afterwards. The lateral orbital wall is exposed, and removed, allowing a fingertip to pass through and leaving the rim intact. Medially, a large part of the ethmoidal bone is removed as far back as the posterior ethmoidal artery. Finally, the medial part of the floor is removed sparing the infraorbital nerve. The periorbita is incised in posteroanterior direction in the posterior part of the orbit and perpendicular to this in the anterior part of

Table 1 Clinical characteristics of 125 patients with Graves'ophthalmopathy who underwent three wall decompression via coronal approach

\begin{tabular}{ll}
\hline Male & 7 \\
Female & 118 \\
Age (years) (SD) & $40.4(10.8)$ \\
Range & $18-68$ \\
Preoperative Hertel values (mm) in 250 eyes & \\
$\quad$ Mean (SD) & $22.43(2.94)$ \\
$\quad$ Range & $15-30$ \\
\hline
\end{tabular}

Table 2 Proptosis reduction according to the preoperative Hertel values

\begin{tabular}{lll}
\hline $\begin{array}{l}\text { Preoperative Hertel } \\
\text { value }\end{array}$ & $\begin{array}{l}\text { Number of } \\
\text { orbits }\end{array}$ & $\begin{array}{l}\text { Proptosis reduction (mm) } \\
(S D)\end{array}$ \\
\hline $\begin{array}{l}\text { Group 1 (<22 mm) } \\
\text { Group 2 (23-25 }\end{array}$ & 124 & $3.4(1.75)$ \\
$\quad$ mm) & 67 & $4.9(1.75)$ \\
$\begin{array}{l}\text { Group 3 (25-27 } \\
\text { mm) }\end{array}$ & 48 & $5.8(2.18)$ \\
Group 4 (> 27 mm) & 11 & $5.8(2.12)$ \\
\hline
\end{tabular}

Difference between group 1 and 2 significant $(p<0.01)$.

Difference between group 2 and 3 significant $(\mathrm{p}<0.05)$.

the orbit. The temporalis muscle is sutured back with 2.0 Mersilene and drains are left in the infratemporal fossae. The skin-muscleperiosteum flap is brought back and closed with skin staples.

\section{Results}

PROPTOSIS REDUCTION

The mean proptosis reduction in the 250 orbits was $4.34 \mathrm{~mm}$ (SD $2.58 \mathrm{~mm}$ ranging from 0 to $10 \mathrm{~mm}$ ). There was no significant relation between duration of the ophthalmopathy and the amount of proptosis reduction $(\mathrm{p}>0.5)$.

We divided the orbits according to the preoperative Hertel measurements. Table 2 shows the proptosis reduction in the four groups. One hundred and twenty four orbits were in group $1(<22 \mathrm{~mm})$, showing a mean proptosis reduction of $3.4 \mathrm{~mm}$. In the second group (23-25 mm), 67 orbits were involved, with a mean proptosis reduction of $4.9 \mathrm{~mm}$. In the 48 orbits with preoperative Hertel values of 25 to $27 \mathrm{~mm}$ (group 3), the mean proptosis reduction was $5.8 \mathrm{~mm}$. Eleven orbits were in group $4(>27 \mathrm{~mm})$ also showed a mean proptosis reduction of $5.8 \mathrm{~mm}$. The differences in proptosis reduction between the first two groups, and between groups 2 and 3 were statistically significant $(\mathrm{p}<0.001$ and $\mathrm{p}<0.05$ respectively).

Sixty patients reached maximum proptosis reduction within 3 months and 88 within 6 months. The remainder of the patients (37) showed a mild progressive decrease in proptosis even after 6 months.

\section{COMPLICATIONS}

Visual loss

None of the 125 patients showed any visual loss.

\section{Motility changes}

The patients were divided into three groups according to motility and diplopia. The first group (-) consisted of patients with normal ocular motility, without any diplopia. The second group $( \pm)$ included patients with restriction of motility and diplopia in the extreme directions of gaze. Patients with evident restriction and diplopia in primary and/or reading positions were included in the third group (+). Table 3 shows the changes in motility and diplopia. Forty nine patients had normal motility preoperatively; in 39 patients it was unchanged postoperatively, whereas in six of them, diplopia developed in the extreme positions. Four patients acquired diplopia in 
Table 3 Motility changes after three wall decompression by coronal approach

\begin{tabular}{ll}
\hline Preoperative & Postoperative \\
\hline $49-$ & $39-$ \\
& $6 \pm$ \\
$29 \pm$ & $4+$ \\
& $28 \pm$ \\
$47+$ & $1+$ \\
& $42+(16$ increased diplopia) \\
& $4 \pm$ \\
& $1-$ \\
\hline
\end{tabular}

- = No motility disturbances $\pm=$ restriction of motility in the extreme directions of gaze; $+=$ restriction of motility with diplopia in primary and reading positions.

the primary and/or reading positions; in all four mainly esotropia developed.

Twenty nine patients had diplopia in the extreme directions of gaze preoperatively. In 28, motility and monocular ductions were unchanged postoperatively, in one patient diplopia in primary gaze developed.

In 47 patients, evident restriction with diplopia in primary and/or reading positions existed preoperatively. In 26 of them ocular motility and monocular ductions were about the same postoperatively with no clear difference in diplopia. In four the motility improved to restriction only in the extreme directions of gaze and in one patient the motility disturbances disappeared completely. In 16 (34\%) of these 47 patients who had evident diplopia preoperatively, diplopia worsened postoperatively. Abduction was decreased in most of them.

\section{Other complications}

In Table 4 the other complications are listed. Almost all patients had a temporary hypaesthesia of the forehead. In none of them did it last longer than 3 months. Seven patients had a one sided hypaesthesia of the infraorbital nerve; in six it was temporary, but in one it was permanent. One patient had a one sided neuralgia of the infraorbital nerve and one of the supraorbital nerve; in both patients the complaints disappeared after surgical exploration, during which fibrosis and small bone fragments were removed.

One patient developed a relative enophthalmos on one side, which was corrected with a silicone block, placed subperiostially on the orbital floor.

In three patients, who had symmetric Hertel readings preoperatively, $3 \mathrm{~mm}$ asymmetry was measured postoperatively. In none of them was correction found to be necessary.

Table 4 Complications after three wall orbital decompression by coronal approach

\begin{tabular}{|c|c|}
\hline Unilateral hypaesthesia & $\mathrm{n}=6$, temporary \\
\hline Infraorbital nerve & $\mathrm{n}=1$ permanent \\
\hline Neuralgia infraorbital nerve & $\begin{array}{l}\mathrm{n}=1 \text {, resolved after } \\
\text { exploration }\end{array}$ \\
\hline Neuralgia supraorbital nerve & $\begin{array}{l}\mathrm{n}=1 \text {, resolved after } \\
\text { exploration }\end{array}$ \\
\hline Enophthalmia (3 mm) & $\begin{array}{l}\mathrm{n}=1, \text { resolved after } \\
\text { implantation of silicone block }\end{array}$ \\
\hline Asymmetry $(3 \mathrm{~mm})$ & $\mathrm{n}=3$, no surgery necessary \\
\hline Unsatisfactory result & $\begin{array}{l}\mathrm{n}=1 \text {, further removal of floor } \\
\text { by anterior approach }\end{array}$ \\
\hline $\begin{array}{l}\text { Recurrence of proptosis after } \\
\text { initial good result }\end{array}$ & $\begin{array}{l}\mathrm{n}=1 \text {, reoperation by coronal } \\
\text { approach }\end{array}$ \\
\hline
\end{tabular}

In one patient the three wall decompression did not lead to a satisfactory result (preoperatively $28 \mathrm{~mm}$, postoperatively $24 \mathrm{~mm}$ ). She underwent a further removal of the orbital floor and medial wall by anterior approach. Another patient had to be reoperated by coronal approach because of a recurrence of the proptosis after a good initial result, probably caused by a recurrence of the intraorbital inflammation.

One patient had a transient increase in proptosis during an episode of sinusitis.

\section{Discussion}

Graves' ophthalmopathy is an inflammatory disease of the orbit, with a poorly understood aetiology. Inflammation of the orbital tissues, which affects especially the extraocular muscles gives rise to an increase in volume of the orbital contents. Because the orbit is a bony cavity which cannot expand, the increased volume can only expand anteriorly, resulting in proptosis. After the inflammation has resolved, spontaneously or as a result of immunosuppressive therapy, the extraocular muscles usually remain enlarged as a result of fibrosis and fatty degeneration.

In the past, the disfiguring sequelae of the ophthalmopathy were treated by tarsorrhaphy and lid lengthening procedures. Orbital decompression was reserved for sight threatening conditions, such as compressive optic neuropathy and severe corneal exposure. These conditions were found to justify the complications of surgery.

The most frequently described complication is postoperative ocular imbalance with diplopia. Walsh and Ogura found an increase in diplopia after a transantral decompression in $33 \%{ }^{1}$ McCord, in his large study, found an incidence of $40.9 \%$ of worsened muscle balance in those cases decompressed by the transantral approach. ${ }^{17}$ Hurwitz and Birt described postoperative esotropia in 16 out of 19 patients operated in that manner. ${ }^{5}$ In the study of Kao et al three of four patients operated transantrally needed surgery for diplopia, although the preoperative orthoptic situation is not mentioned. ${ }^{7}$ Garrity and his coworkers studied 446 patients who had undergone a transantral decompression; 64\% developed new diplopia postoperatively. ${ }^{9}$ Fatourechi et al found an incidence of $25 \%$ new diplopia after transantral decompression. ${ }^{14}$

The other approaches for decompression of the orbit also show a varying incidence of worsened muscular imbalance. Fells found an increased amount of diplopia in 11 of 14 patients, decompressed via an anterior ethmoidectomy, ${ }^{15}$ while Linberg and Anderson described a $30 \%$ new diplopia in their subciliary two wall decompressions. ${ }^{2}$ Hurwitz and Birt performed an anterior ethmoidectomy in four patients; three of them showed a postoperative esotropia. ${ }^{5}$ The three wall decompression through a modified blepharoplasty incision, described by Antoscyk, resulted in new diplopia in one out of 11 patients. ${ }^{12}$ Lyons and Rootman found new diplopia in four out of 22 
patients who underwent a decompression via a Lynch incision. One of the nine patients operated via a translid approach developed postoperative esotropia. ${ }^{13}$ In the study of McCord, in which he performed a three wall decompression through lateral canthal and inferior fornix incision, a preoperative diplopia of $80 \%$ was seen, whereas no increase in diplopia was found postoperatively. ${ }^{4}$ Leatherborrow et al, who carried out a three wall decompression via a coronal approach in 10 patients, showed $60 \%$ new diplopia postoperatively. ${ }^{8}$ Mourits et al studied 21 patients decompressed via the coronal approach and found only $10 \%$ worsening of the motility disorders. ${ }^{11}$

In the present study, new postoperative diplopia in primary and/or reading positions developed in only $3.2 \%$ of the patients. Another $4.8 \%$ developed diplopia in the extreme directions of gaze. The low incidence of postoperative new diplopia in our study can be attributed to a number of factors. First of all, because the population in our study consisted mainly of patients with mild to moderate ophthalmopathy, the degree of myopathy can be considered less than in the patients in the studies mentioned above. When we looked at the subpopulation with marked ophthalmopathy - that is, diplopia in primary direction of gaze and in reading position, 16 of 42 patients $(34 \%)$ showed increased diplopia. In the second place, maximum decompression was not aimed for in every patient; in patients with lower preoperative Hertel readings, less bone removal and less intraorbital manipulation were necessary. Another factor contributing to the low incidence of new postoperative diplopia is the symmetric relaxation of the orbital tissues, which is made possible by the way in which the periorbita can be incised in four quadrants by the coronal approach. ${ }^{22}$

Removal of the medial orbital wall contributes most to the decompression and that may be the reason that esotropia is the most frequent form of new diplopia after the three wall decompression via coronal approach.

In our patients the mean preoperative Hertel measurement was $22.4 \mathrm{~mm}$ with a reduction of $4.34 \mathrm{~mm}$. In the literature preoperative Hertel values range from 24 to $26.4 \mathrm{~mm}$, with a proptosis reduction ranging from 4 to $7 \mathrm{~mm}$. A clear correlation between amount of preoperative proptosis and amount of reduction is evident in most studies, ${ }^{268912-14}$ which is in agreement with our findings. Patients with a preoperative Hertel value of $25 \mathrm{~mm}$ or more showed a mean proptosis reduction of $5.8 \mathrm{~mm}$, indicating that the three wall decompression by coronal approach is as effective as other approaches. However, in patients with less absolute preoperative proptosis, who were found to be suitable for proptosis reduction judged on predisease photographs (Fig 1), all of the medial floor was not removed in order to achieve proptosis reduction.

Because maximum proptosis reduction was reached within 6 months in $70 \%$ of the patients and within 9 months in $88 \%$, our policy is to postpone corrections of the eyelids to approximately 6 months after the three wall decom- pression because of the influence of the positions of the eyeballs on the eyelids.

Complications, like damage of the supraorbital nerve, were rare probably because of the relatively good visualisation. By removing only the medial part of the orbital floor the infraorbital nerve could be avoided and was therefore rarely damaged. During the first years in which the coronal approach was used some patients showed a slight deepening of the superior anterior temporalis space because of disinsertion of the temporalis muscle. But since we started to use 2.0 Mersilene instead of 5.0 Vicryl to suture the muscle back this complication is no longer seen.

Because of exposure of the coronal incision in men with acquired male pattern hair loss, not every male patient was considered suitable for the coronal approach. This, in addition to the fact that women are affected six times as much by Graves' ophthalmopathy as men, explains the overwhelming number of women in this study.

In conclusion, this large retrospective study shows that the three wall orbital decompression by coronal approach is a safe and effective technique to achieve proptosis reduction in patients with disfiguring proptosis due to Graves' ophthalmopathy. The major advantage with regard to other three wall approaches is the invisibility of the scar in patients with the appropriate hair implant. The low incidence of new postoperative diplopia is partly determined by the patient population of our study. The indication for operation and the amount of intended proptosis reduction should not be determined only on the absolute Hertel values, but also on an estimation of the increase in proptosis as judged on old photographs of the patient's face.

1 Walsh TE, Ogura JH. Transantral orbital decompression for malignant exophthalmus. Laryngoscope 1957;67:544-67. Linberg JV, Anderson 1A. Transorbital decompression. Indications and results. Arch Ophthalmol 1981;99:113-9.

3 Thaller SR, Kawamota HK. Surgical correction of exophthalmus secondary to Graves' disease. Plast Reconstr Surg thalmus second 86 :411-8.

4 McCord CD. Orbital decompression for Graves' disease. Exposure through lateral canthal and inferior fornix incision. Ophthalmology 1981;88:533-41.

5 Hurwitz JJ, Birt D. An individualized approach to orbital decompression in Graves' orbitopathy. Arch Ophthalmol 1985;103:660-5.

6 Warren JD, Spector JG, Burde R. Long-term follow-up and recent observations on 305 cases of orbital decompression for dysthyroid orbitopathy. Laryngoscope 1989;99:35-40.

7 Kao SCS, Chang T-C, Ho P-K. Surgical management of Graves' ophthalmopathy: stage 1, inferomedial decompression. F Formosan Med Assoc 1992;91:1154-61.

8 Leatherborrow B, Lendrum J, Mahaffey PJ, Noble JL, Kwartz J, Davies H. Three wall orbital decompression for Gwartz J, Davies H. Three wall orbital decompression for 5:456-65.

9 Garrity JA, Fatourechi V, Bergstrahl EJ, Bartley GB, Beatty CW, DeSanto LW, et al. Results of transantral orbital decompression in 428 patients with severe Graves' ophthalmopathy. Am F Ophthalmol 1993;116:533-47.

10 Harting F, Koornneef L, Peeters HJF, Gilissen JPA Fourteen years of orbital decompression in Graves' disease. Orbit 1986;5:123-9.

11 Mourits PhM, Kooruneef L, Wiersinga MW, Prummel MF, Berghout A, van der Gaag R. Orbital decompression for Graves'ophthalmopathy by inferomedial, by inferomedial plus lateral, and by coronal approach. Ophthalmology 1990; 97:636-41.

12 Antoszyk JH, Tucker N, Codere F. Orbital decompression for Graves' disease: exposure through a modified blepharoplasty incision. Ophthalmic Surg 1992;23:516-21.

13 Lyons CJ, Rootman J. Orbital decompression for disfiguring exophthalmus in thyroid orbitopathy. Ophthalmology 1994; 101:223-30. 
14 Fatourechi V, Garrity JA, Bartley GB, Bergstrahl EJ, DeSanto LW, Gorman CA. Results of transantral decompression performed primarily for cosmetic indications. Ophthalmology 1994;101:938-42.

15 Fells P. Orbital decompression for severe dysthyroid eye disease. Br F Ophthalmol 1987;71:107-11.

16 Elisevich K, Allen L, Bite U, Colcleugh R. Decompression for dysthyroid opthalmopathy via the orbital rim approach f Neurosurg 1994;80:580-3.

17 McCord C. Current trends in orbital decompression. Oph thalmology 1985;92:21-33.

18 Tessier P. Expansion chirurgicale de l'orbit. Ann Chir Plast 1969;14:207-14
19 Krastinova D, Rodallec A. Basedown orbitopathy. [French] Ann Chir Plas Esthet 1985;30:351-8.

20 Koornneef L, Mourits M. Orbital decompression for decreased visual acuity and for cosmetic reasons. Orbit 1988;7:225-38.

21 Van der Pol JP, Koornneef L, Gillissen JPA. Chirurgische rehabilitatie bij patienten met Graves-oftalmopathie; gunstige resultaten van orbitadecomptessie via coronale benadering. Ned Tijdschrift Geneeskd 1992;136:1971-4.

22 Koornneef L. Orbital bony and soft tissue anatomy. In: The eye and orbit in thyroid disease. New York: Raven Press, 1984:5-23. 